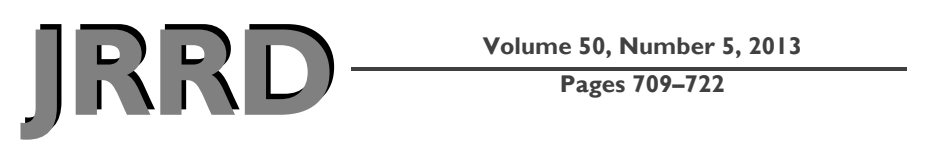

\title{
New method of fixation of in-bone implanted prosthesis
}

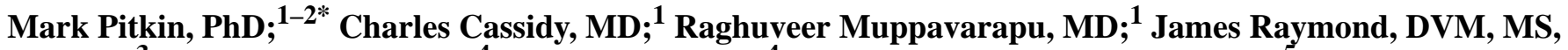 \\ DACVP; ${ }^{3}$ Maxim Shevtsov, MD $;^{4}$ Oleg Galibin, MD ${ }^{4}$ Serge D. Rousselle, DVM, DACVP ${ }^{5}$ \\ ${ }^{1}$ Tufts University School of Medicine, Boston, MA; ${ }^{2}$ Poly-Orth International, Sharon, MA; ${ }^{3}$ Charles River Laborato- \\ ries Pathology Associates, Frederick, MD; ${ }^{4}$ I.P. Pavlov State Medical University, St. Petersburg, Russia; ${ }^{5}$ Alizée \\ Pathology LLC; Thurmont, MD
}

\begin{abstract}
This article presents results on the effectiveness of a new version of the titanium porous composite skin and bone integrated pylon (SBIP). The SBIP is designed for direct skeletal attachment of limb prostheses and was evaluated in a preclinical study with three rabbits. In accordance with the study protocol, a new version of the pylon (SBIP-3) was implanted into the hind leg residuum of three rabbits. The SBIP-3 has side fins that are designed to improve the bond between the bone and pylon. The fins are positioned inside two slots precut in the bone walls; their length can be adjusted to match the thickness of the bone walls. After 13 (animal 1) or 26 (animals 2 and 3) wk, the animals were sacrificed and samples collected for histopathological analysis. The space between the fins and the bone into which they were fit was filled with fibrovascular tissue and woven bone. No substantial inflammation was found. We suggest that if further studies substantiate the present results, the proposed method can become an alternative to the established technique of implanting prostheses into the medullary canal of the hosting bone.
\end{abstract}

Key words: arthroplasty, bone, direct skeletal attachment, infection, limb amputation, osseointegration, porous pylon, prosthesis, prosthetic rehabilitation, residuum.

\section{INTRODUCTION}

In direct skeletal attachment (DSA) of limb prostheses, a pylon is implanted transcutaneously into the bone of a limb's residuum. A specific procedure, called Osseointegrated Prostheses for the Rehabilitation of Amputees
(OPRA), and the attendant instrumentation (Integrum AB; Mölndal, Sweden) have been developed and implemented [1]. In this original, two-stage technique, a threaded cylindrical fixture is first screwed into the medullary canal of the hosting bone. A second surgery is performed after several months to screw the transcutaneous abutment into the fixture [2].

There remain major problems, including how to consistently create an infection-free seal of skin around the pylon [3-7]. The quality of the pylon-bone interface is also an issue that must be investigated further. Experience in total joint replacement with implantation of stems into the medullary canal shows that loosening of the prostheses remains a serious problem [8-10]. An uncemented, porous-coated stem enables bone ingrowth, but stress shielding (leading to proximal bone loss) can be a long-term problem [11].

\footnotetext{
Abbreviations: $\mathrm{BA}=$ bone area, $\mathrm{BIC}=$ bone-implant contact, DSA $=$ direct skeletal attachment, FEA = finite element analysis, $\mathrm{H} \& \mathrm{E}=$ hematoxylin and eosin, IS = implant surface, MMA $=$ methyl methacrylate, $\mathrm{ROI}=$ region of interest, $\mathrm{rTtBIC}=$ regional total bone in contact with implant, $\mathrm{SBIP}=$ skin and bone integrated pylon, SBIP-3 = SBIP with side fins.

*Address all correspondence to Mark Pitkin, PhD; Physical Medicine and Rehabilitation, Tufts University School of Medicine, 145 Harrison Ave, Boston, MA 02111; Poly-Orth International, Sharon, MA 02067.

Email: mpitkin@tuftsmedicalcenter.org

http://dx.doi.org/10.1682/JRRD.2012.11.0202
} 
Longevity of the pylon-bone interface in DSA is even more important than in arthroplasty. Since the DSA procedure is indicated mostly in patients with a short residuum, any revision that shortens the hosting bone significantly compromises the rehabilitation outcomes [1214]. Implantation into the medullary canal redistributes stresses in the bone and the implant, with partial removal of stress from the bone. This effect, called stress shielding, increases the porosity of the cortical bone that hosts the implant, relative to the ipsilateral bone [15]. The outcomes of stress shielding are reduction in hosting bone strength [16-17] and cortical thinning in the distal zones, which increases with time [18]. The weakening and thinning increase the risk of failure, especially among young patients who are involved in more active locomotion [19-20].

The porous composite skin and bone integrated pylon (SBIP) system was developed by Poly-Orth International (Sharon, Massachusetts) with several modifications [21]. The system was intended for a one-stage DSA procedure [22], similar to the Percutaneous Osseointegrated Prostheses system (POP) (IMDS Co-Innovative; Logan, Utah) [23], Endo-Exo Femoral Prosthesis (EEFP) (Eska Orthodynamics $\mathrm{GmbH}$ [formerly ESKA IMPLANTS AG]; Lubeck, Germany) [24], and the Intraosseous Transcutaneous Amputation Prosthesis (ITAP) system (Stanmore Group [University College; London, United Kingdom]) [25]. Recent modifications of the SBIP system allow for its use in a two-stage procedure [26].

As was shown in a recent review [26], the SBIP is principally distinguished from other systems for DSA because it provides conditions for the ingrowth of skin and bone cells throughout the entire volume of the implant [27-28]. Histological analysis demonstrated that the porosity, volume fraction, and pore size in the SBIP implants were conducive for cells to grow throughout the volume of the implant effectively [29]. Mechanical tests showed that the strength of the composite implant [3031] was superior to other porous constructs [32-33].

Considering the importance of maintaining the implant's bond with the bone, we suggested adding side elements (fins) to the SBIP porous composite implant [34] to better fix the implant. The fins are meant to reduce the risk of implant subsidence and stress shielding. It was hypothesized further that placing the fins into precut slots in the bone walls would stimulate the regeneration of the bone cells in the circular direction relative to the bone longitudinal axis instead of the radial regener- ation seen during total joint replacement $[13,35]$. The circular regeneration and the longitudinal regeneration are natural components of bone fracture healing. They were utilized in a creative way by Dr. Ilizarov in his method of distractional ostheogenesis [36]. The method is used to lengthen bones by moving bone fragments apart in a fixating apparatus in the longitudinal direction. The method allows also for bone widening, when the bone fragments are moved apart perpendicularly to the bone's longitudinal axis [37]. The latter relies on the mechanism of circular ossification, which has never been applied to lock devices implanted into the medullary canal.

Circular ossification is driven by the mechanism of distraction osteogenesis (Figure 1), which forms strong bone tissue throughout the entire thickness of the bone walls [13]. Circular ossification, therefore, was thought to create a more reliable implant-bone bond. To activate the circular ossification, the fins are carefully press-fitted into the slots in the bone walls. The snug fit slightly moves the slot's walls apart, creating an Ilizarov-type distraction. At the same time, the bone's elastic resistance to distraction requires the walls of the slot to move back, which is the analog of the compression that Ilizarov's apparatus provides (Figure 2(b)) [38].

A finite element analysis (FEA) showed the mechanical advantages of the fins in reducing the stress shielding on the distal edge of the hosting bone compared with the cylindrical implants [31]. In the FEA study, a computeraided design model of the pylon with three pairs of fins (Figure 3) was loaded with bending moments, simulating those in the stance phase of normal gait and providing direct impact on the longevity of the implantation. The FEA demonstrated stress in the bone's distal zone two times less than of an implant with a cylindrical shape.

The current article presents the results of an animal study aimed at evaluating the process of bone reconstruction in the precut slots of the bone walls after implantation of the SBIP with side fins (SBIP-3).

\section{METHODS}

\section{Development of Composite Porous Pylon with Side Fins (SBIP-3)}

The composite porous pylon SBIP-3 manufactured for this study (Poly-Orth International) has a solid insert with a cross-shaped cross section (Figures 4 and 5). The web is $1 \mathrm{~mm}$ thick and $3 \mathrm{~mm}$ wide. The inserts were 


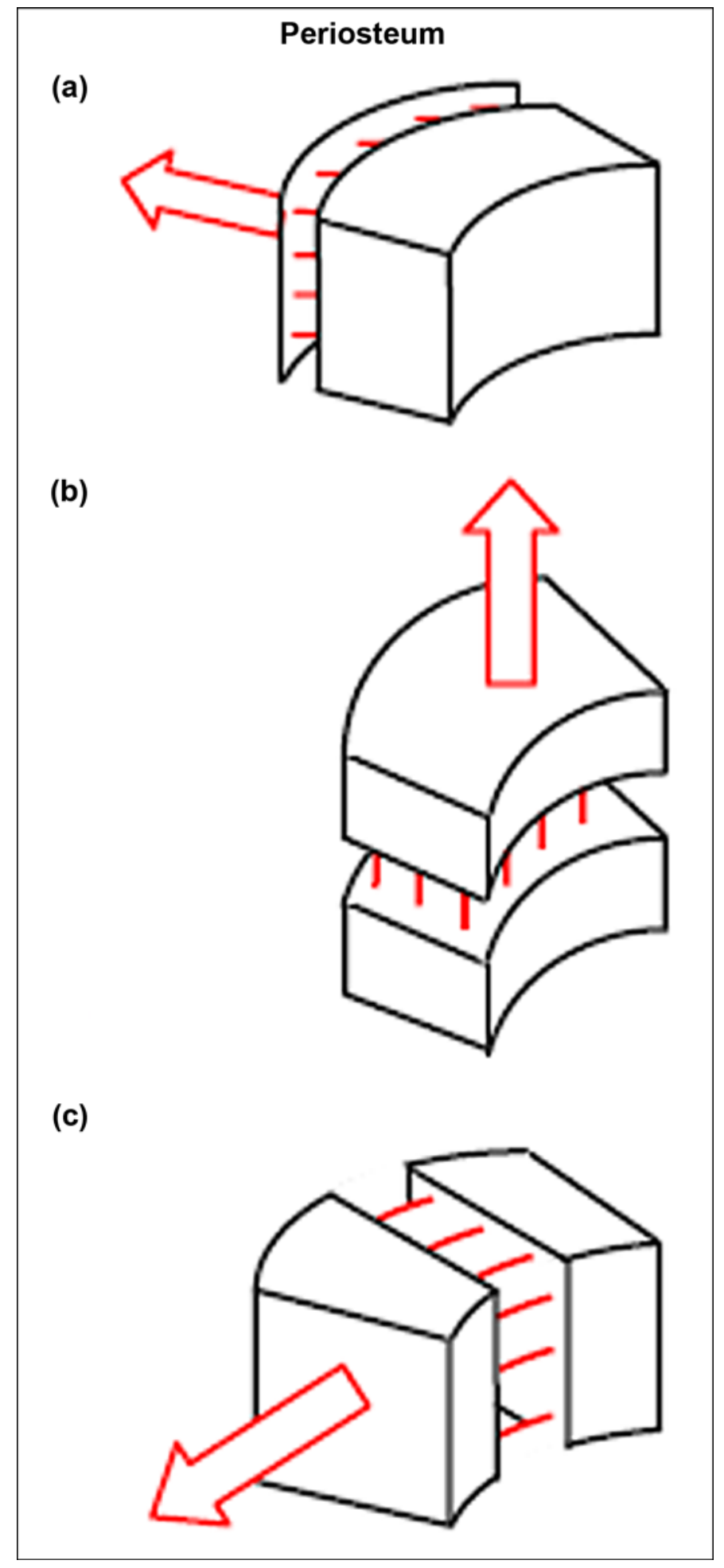

Figure 1.

Ossification (indicated by multiple lines) in response to pulling forces: (a) from muscles applied to periosteum, (b) by lengthening, and (c) by widening. Figure adapted from Pitkin [13]. machined (Payne Engineering and Fabrication Co, Inc; Canton, Massachusetts) using $3 \mathrm{~mm}$ round rods (Ti6AL4V ELI) (SmallParts; Seattle, Washington).

The molds for sintering of the pylons were fabricated by Payne Engineering and Fabrication Co, Inc, from boron nitride (Momentive; Columbus, Ohio). The solid inserts were positioned in the molds and sintered with the Ti6AL-4V ELI powder sieved to a $(-80+200)$ mesh. Sintering was conducted by ADMA Products Group (Hudson, Ohio) for 4 hours at $1,090{ }^{\circ} \mathrm{C}$. The porosity and pore size ranged between 45 and 50 percent and 30 and $200 \mu \mathrm{m}$, respectively [39]. These parameters were consistent with recommendations for better skin and bone cells adhesion, proliferation, and differentiation [40-44]. The outer diameter of the cylindrical porous cladding was $5 \mathrm{~mm}$.

Holes $0.5 \mathrm{~mm}$ in diameter, into which the fins were to be inserted, were drilled through and perpendicularly to the longitudinal axis of the pylon, as shown with red dashed lines in Figure 4. In an embodiment shown in Figure 5(a), the fins are made from threaded studs $0.5 \mathrm{~mm}$ in diameter (ANITRIN; Fallbrook, California). The threads allowed the fins' length to be adjusted to the thickness of the hosting bone (Figure 3). In an embodiment shown in Figure 2(b), the fins are made from straight pieces of wire $0.5 \mathrm{~mm}$ in diameter. To adjust to the thickness of the bone walls, the fins were bent (Figure 5(c)).

\section{In Vivo Animal Experiments}

\section{Procedures}

Three white New Zealand rabbits were used in the study. Two of them were treated at the Pine Acres Research Facility (Norton, Massachusetts), following Institutional Animal Care and Use Committee approval of the protocol. The third animal was treated at the I.P. Pavlov State Medical University (St. Petersburg, Russia), with all procedures approved by the ethics committee of the I.P. Pavlov University. The investigators at both of the sites used the same study protocol. The technique for amputation and the following implantation has been described previously [39]. Prior to incision, we placed a tourniquet on the rabbits' thigh. The leg was then sterilely prepped using the usual technique. We then identified the knee joint and measured $4 \mathrm{~cm}$ distal to the tibial articular surface. A circumferential incision was made over the proximal tibia with a posterior skin flap to allow for tension-free closure. The muscles and tendons at this level were transected using monopolar cautery. We 


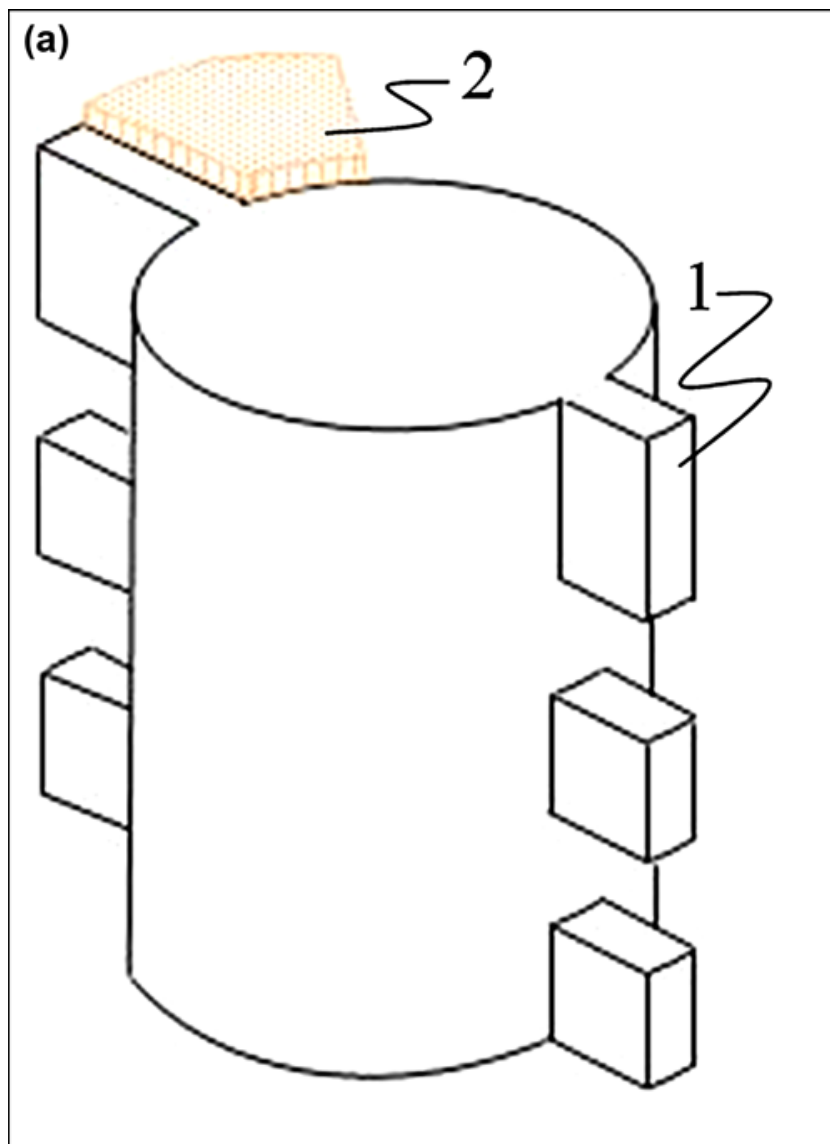

(b)

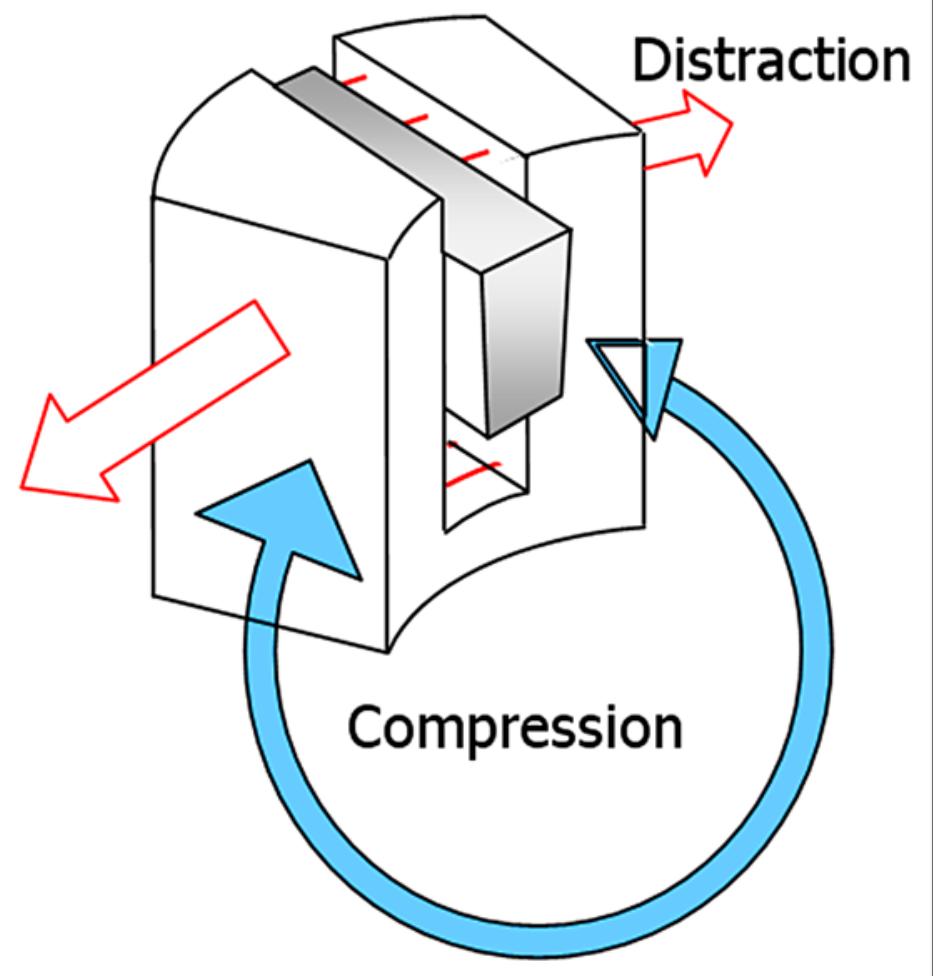

Figure 2.

(a) Schematic view of implant with side fins "1" positioned in precut slot in bone walls "2." Figure adapted from Pitkin et al. [28].

(b) Press-fitting of fin ("1" in (a)) to slot in bone wall results in llizavov-type distraction (red arrows) and compression (blue arrow) due to elastic resistance of bone wall to widening.

identified the anterior and posterior neurovascular bundles, which were then ligated and transected. Soft tissue attachments were stripped off the tibia to the level $1 \mathrm{~cm}$ proximal to the intended site of the osteotomy. An oscillating saw was then used to make the tibial and fibular osteotomy. The fibula was rongeured down 2 to $3 \mathrm{~cm}$ proximal to the level of the tibial osteotomy. Any remaining soft tissue was transected using monopolar cautery, thereby completing the amputation.

A curette was used to broach the medullary canal of the tibia. Two $2 \mathrm{~cm}$ longitudinal tibial slots were then made approximately $180^{\circ}$ apart using an oscillating saw (Figure 6). A mallet was used to insert the implant into the tibial medullary canal. Prior to closure, the fat and subcutaneous tissue of the posterior skin flap was sharply excised to the level of the dermis.
The gastrocnemius muscle was debulked, and the wound was copiously irrigated with normal saline. A small stab incision was made in the flap using a 10 blade for the implant to exit. The dermal portion of the posterior skin flap was laid directly over and made contact with the distal end of the tibia. The wound was then closed with a 4-0 nylon suture with minimal tension. Prior to closure, special care was taken to ensure that the skin flap was in contact with the porous portion of the implant. Once closure was complete, a dry sterile dressing was placed. Position of the implant was confirmed both during and after each procedure using fluoroscopy (Figure 7).

The first animal received the SBIP-3 pylon with threaded fins (Figure 5(a)), and was sacrificed after 13 weeks. After inspecting the animal, we predicted that a longer postsurgery period would be beneficial for bone 


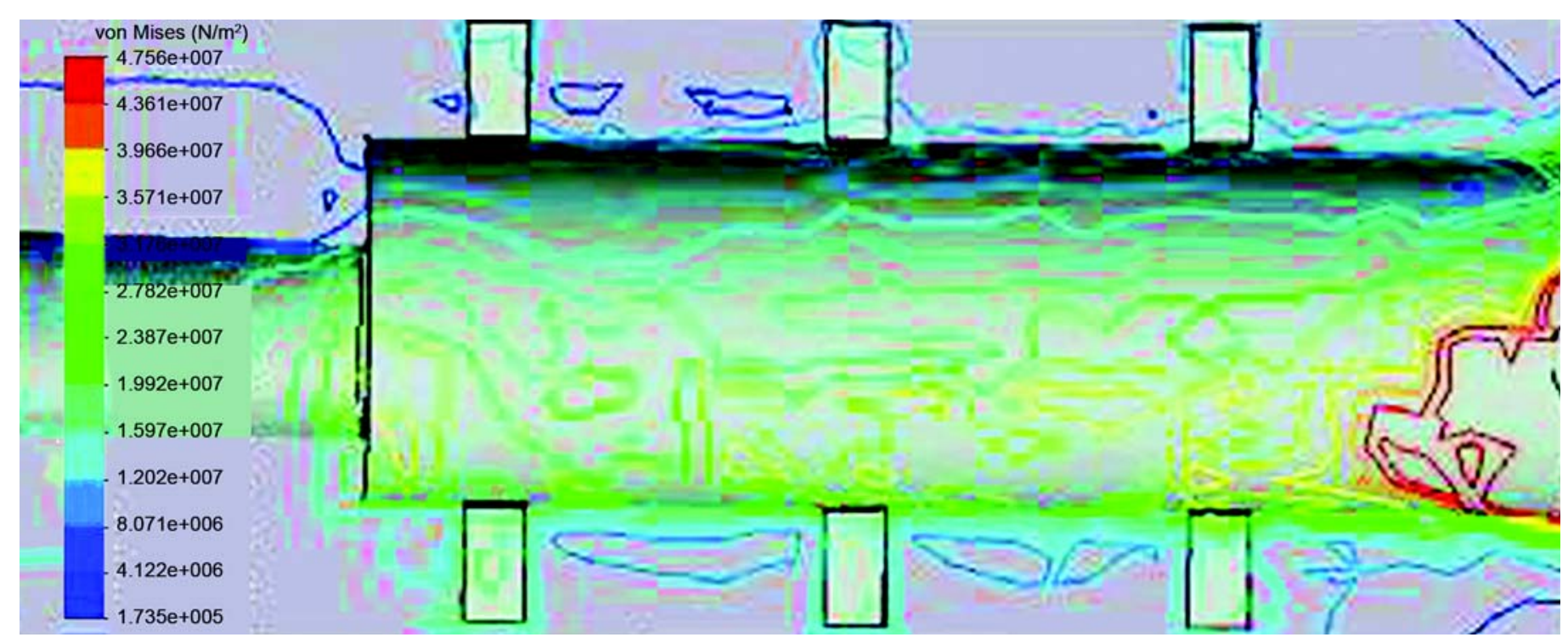

Figure 3.

Von Mises stress distributions in skin and bone integrated pylon with fins [SBIP-3] bone-pylon system in medial-lateral cross section. Figure adapted from Pitkin et al. [30].

remodeling. Correspondingly, animal 2 (which received the SBIP-3 pylon with bent wire fins [Figure 5(c)]) and animal 3 (which received the SBIP-3 pylon with threaded fins [Figures 5 (a) and 8]) were sacrificed after 26 weeks.

\section{Histopathological Analysis}

After 13 and 26 weeks from the time of implantation, respectively, animals 1 and 2 were sacrificed, and the samples were taken for histology study at the Charles River Laboratories Pathology Associates (Frederick, Maryland) [45]. The histology study was conducted by Dr. James Raymond. The plane of the cross section of the implanted pylon and the surrounding tissues is identified by dashed line in Figure 7. The implants were processed, infiltrated, and embedded in methyl methacrylate (MMA) according to standard operating procedures. Each block was sectioned twice. One cross section perpendicular to the device, approximately $50 \mu \mathrm{m}$ in thickness, was obtained above the device-anchoring side fins. One longitudinal section, approximately $50 \mu \mathrm{m}$ thick, was obtained through the remaining device. Slides were scanned at $20 \times$ or $40 \times$ using a ScanScope CS (Aperio; Vista, California). All sections were obtained utilizing the Exakt system (Exakt Technologies, Inc; Oklahoma City, Oklahoma) and surface stained using hematoxylin and eosin (H\&E).

Animal 3, like animal 2, was sacrificed after 26 weeks. A sample of the implanted femoral section was collected, fixed in 10 percent formalin, and shipped to Alizée Pathology, LLC (Thurmont, Maryland) for processing and evaluation. The femoral sample was trimmed and embedded in MMA. The block was bisected: one half was cut to generate four transverse cross-section levels per implant (bone/implant interface). All slides were stained with H\&E. All resulting slides were evaluated by Dr. Serge D. Rousselle for inflammation (including the presence of heterophils/neutrophils, eosinophils, lymphocytes, plasma cells, macrophages, and multinucleated cells), tissue response, and general healing (fibrosis, pseudobursa, osteogenesis) [46].

Histomorphometry was performed at Alizée using Image-Pro ${ }^{\circledR}$ Plus software (Media Cybernetics, Inc; Rockville, Maryland). Morphometric analysis was performed on the longitudinal femur section. The following morphometric data were collected and analyzed: for each section, a region of interest (ROI) was selected based on guidance from the study pathologist. This ROI was bisected longitudinally into two sub-ROIs, Side A and Side B. Within each sub-ROI, the ROI area, bone area (BA), implant surface (IS), and bone-implant contact (BIC) were measured (Table).

Along surfaces extending into the body of the implant but exposed to tissue, IS and BIC were measured to the depth of the porous portion of the implant.

To calculate sub-ROI or surface in each section, we summed individual measurements of a particular parameter 


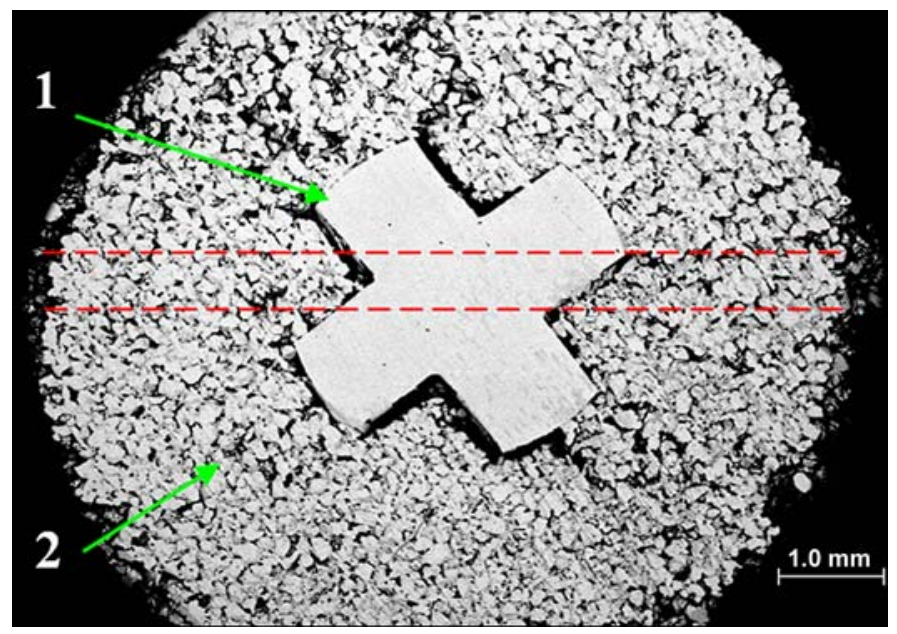

Figure 4.

Cross section of skin and bone integrated pylon with fins (SBIP3) with solid cross-shape insert "1" and surrounding porous cladding "2." Sample was metallographically polished down to 6 microns. Red dashed lines show projection of $0.5 \mathrm{~mm}$ holes for fins (see Figure 5).

(BA, IS, or BIC) to calculate a total value for that parameter in that region. For example, all BIC measurements in section 1-5, Side B, distal surface were summed to calculate the rTtBIC (regional total bone in contact with implant) for that specific region. The values for each parameter in each region were summed to calculate values for the entire section. Proportional values (percentages) were calculated from the parameter totals. From IS and BIC, the percentage of the IS with BIC (BIC percent) were calculated for each region by dividing the rTtBIC by the total IS for the same region and multiplying the result by 100 . Images were calibrated using calibration $10 \times$ scale 4 , with a ratio of 0.247 pixels per micrometer in the $x$ - and $y$-axes. At this spatial calibration, linear measurements are limited to a precision of not better than $10 \mu \mathrm{m}$ and area measurements are limited to a precision of not better than $1,000 \mu \mathrm{m}^{2}$. Morphometry data are presented in the Table.

\section{RESULTS}

In animal 1, 13 weeks after implantation, complete bone regeneration healing was observed in one of the two precut slots (Figure 9). The other slot was not filled with bone cells. The magnification used to capture the image

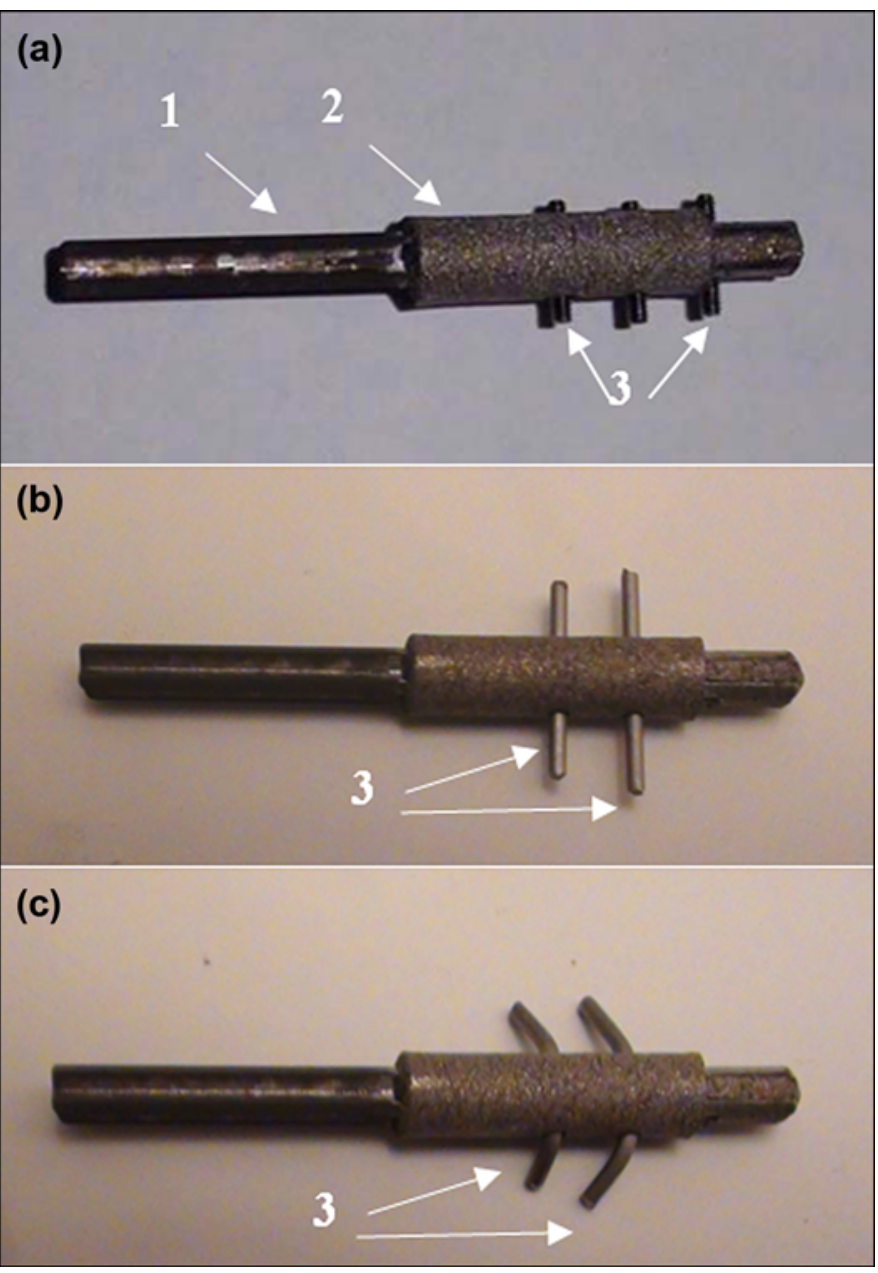

Figure 5.

Preparation of composite porous skin and bone integrated pylon with fins (SBIP-3) for implantation. (a) Pylon with solid insert "1," porous cladding "2," and threaded fins "3." (b) Initial shape of wire fins "3." (c) Final shape of wire fins "3" after bending in order to adjust to entire thickness of hosting bone walls (see Figure 4).

is represented in the figure legend as " $\times$ " preceded by a number (i.e., $4 \times$ is 4 times magnification).

For animal 2, Figure 10 illustrates a photomicrograph of an individual cross section of the SBIP-3 implant and surrounding bone to demonstrate the bonedevice interface. The photograph gives evidence of the ingrowth of bone and fibrovascular cells into both precut slots in the bone walls. There was no histological evidence of the precut slots in the bone in the cross section, indicating that the slots had completely healed. Minimal inflammation was observed multifocally surrounding the 


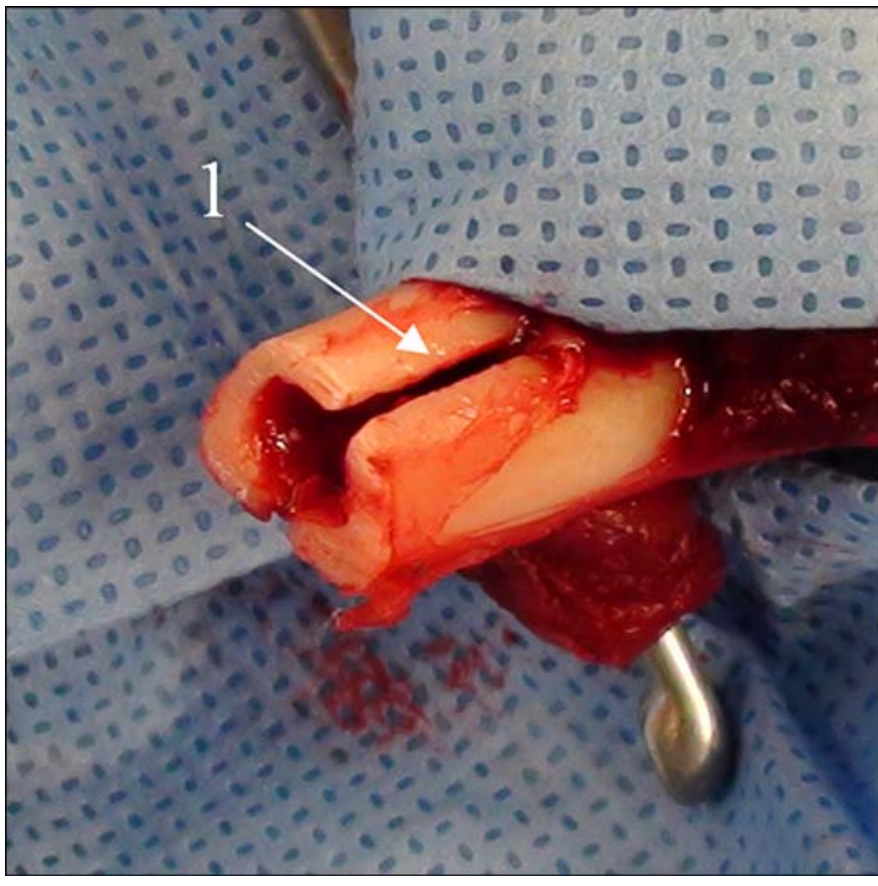

Figure 6.

Precut of slots "1" in bone for placement of implant's side fins.

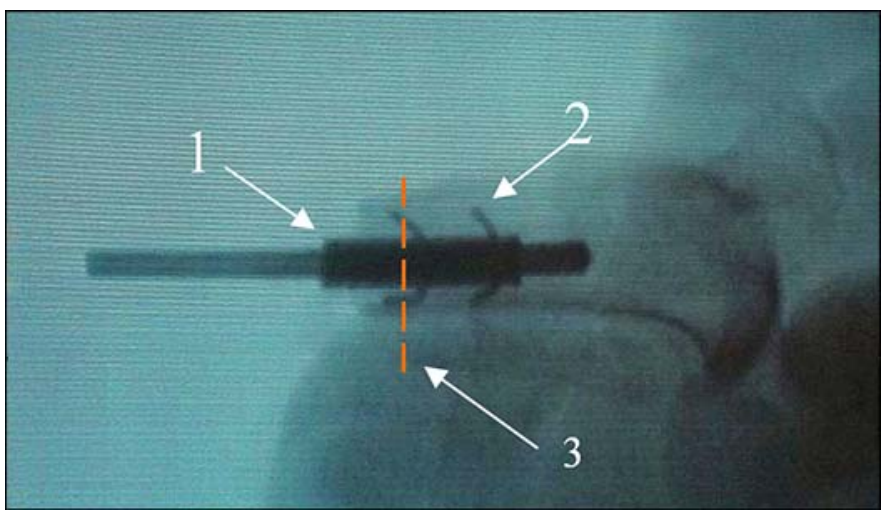

Figure 7.

Animal 2. X-ray of pylon "1" (see Figure 5(c)) with side elements "2" after implantation to bone with the precut slots (see Figure 6). Red dashed line "3" shows plane of histology cross section (see Figure 10).

implant and was characterized by neutrophils and macrophages, most of which were degenerative or necrotic and admixed with cellular debris and small fragments of bone. The inflammation did not appear to extend into the implant or into the long bone. Surrounding the inflammation and cellular debris was a continuous circumferential

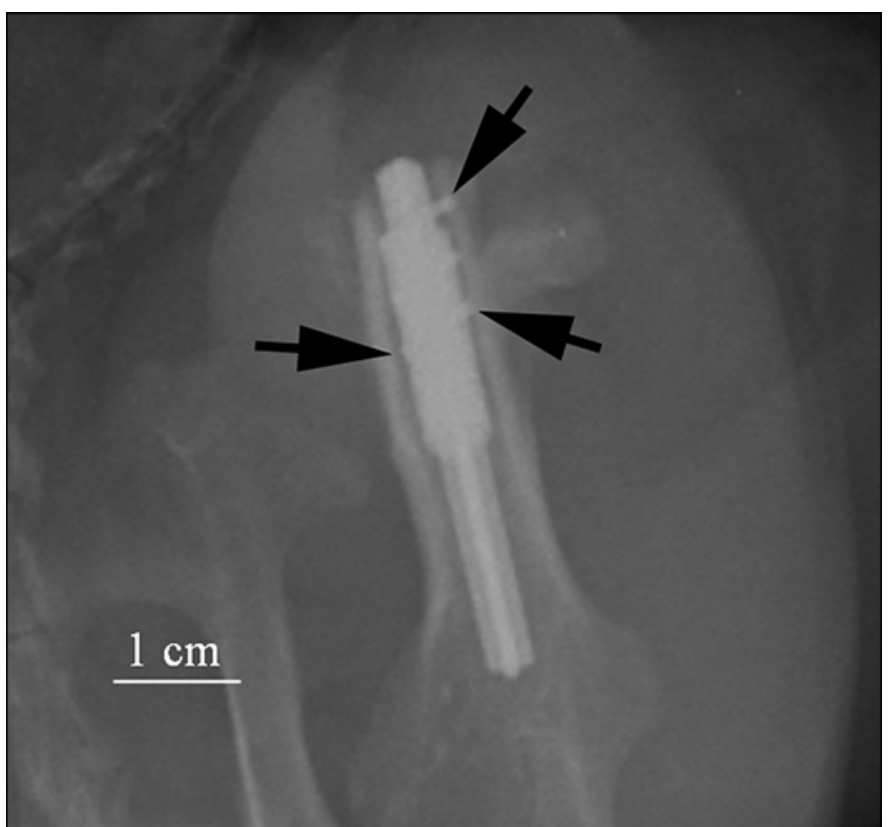

Figure 8.

Animal 3. X-ray of implanted prosthesis (oblique view) in first week. Side fins of pylon inside bone walls are shown by black arrows. Imaging parameters of radiography were $70 \mathrm{kV}$ and 8 mAs (Kodak computed radiography system).

band of fibrovascular connective tissue infiltrated by small islands of woven trabecular bone and very low numbers of inflammatory cells. In no area did the implant appear to be in direct contact with the long bone; however, endosteal bony proliferation was in very close proximity to the device in the single examined cross section. Also, there was near uniform (approximately 90\%) filling of internal device pores with fibrovascular connective tissue or bone (Figure 11) and formation of blood vessels in the pores (Figure 12).

In animal 3, the amputation line showed ideal bone repair characterized by complete entrapment of the device head into a newly formed ossified callus at the level of the distal fin (Figure 13). There was also direct bone apposition along the sides of the fin and the adjacent pylon surfaces as well as along the porous titanium pylon at the distal callus level (Figure 14). The body of the pylon was not in direct contact with the inner cortex proximally. However, there were sparse trabeculae of newly formed bone that occasionally crossed the gap in the two distal-most levels (in the fin area) and direct contact distally between the callus, the porous pylon, and the central crux pylon (Figure 13). The fin ends were frequently 
Table.

Tabulated morphometric data for animal 3 for site 1, block 5 .

\begin{tabular}{lcccccc}
\hline Sub-ROI & ROI $\left.\mathbf{( m m}^{\mathbf{2}}\right)$ & BA $\left.\mathbf{( m m}^{\mathbf{2}}\right)$ & BA (\%) & BIC (mm) & IS (mm) & BIC (\%) \\
\hline A & 27.18 & 1.98 & 7.30 & 6.99 & 30.78 & 22.71 \\
B & 34.20 & 4.49 & 13.14 & 4.63 & 22.74 & 20.36 \\
Total & 61.37 & 6.48 & 10.56 & 11.62 & 53.52 & 21.71 \\
\hline
\end{tabular}

$\mathrm{BA}=$ bone area, $\mathrm{BIC}=$ bone-implant contact, $\mathrm{ROI}=$ region of interest, $\mathrm{IS}=$ implant surface .

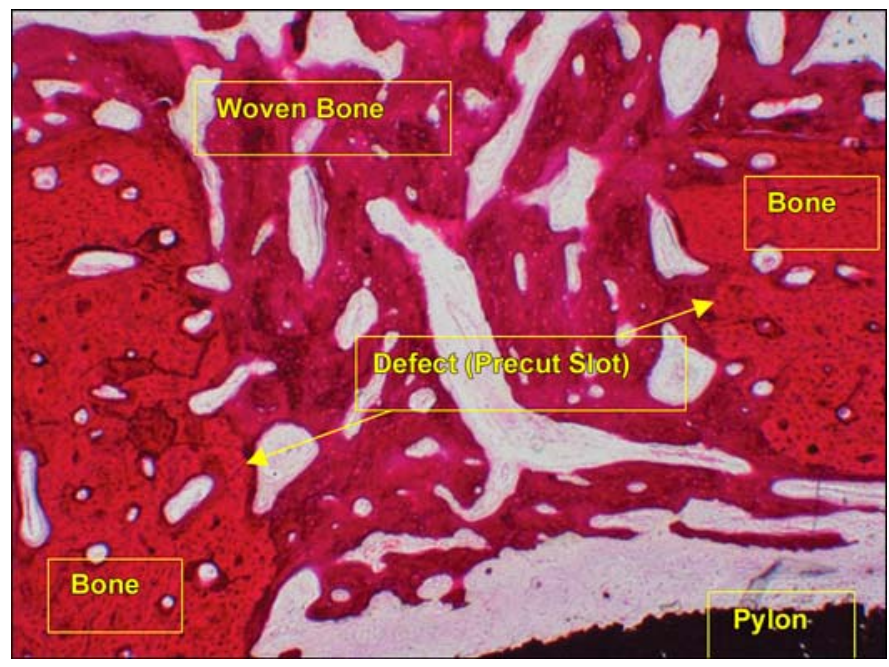

Figure 9.

Healed precut slot (hematoxylin and eosin $4 \times$ ) in animal 1 . Thirteen weeks after implantation.

capped by directly apposed new bone trabeculae. There was no appreciable inflammatory response along the titanium pylon.

The very tip of the pylon was surrounded by a thin layer of fibrous connective tissue that infiltrated the polymer mesh and sat within a well-formed bursa (Figure 15). The outer most layer of the bursa was comprised of densely collagenous connective tissue with no inflammation or focal ossification; it also contained occasional weaved suture material or ties (Figure 16). The pylon remained covered by a musculo-adipose flap, and a welldifferentiated bursa was formed along the tip of the pylon with no evidence of chronic trauma.

Morphometry measurements showed that while relative BIC values were low, there was still good structural contact between the callus and the pylon, namely at the level of the distal fin (Table). The sequential sections across the femur shaft showed no evidence of instability (no granulation tissue, encapsulation, or scar tissue

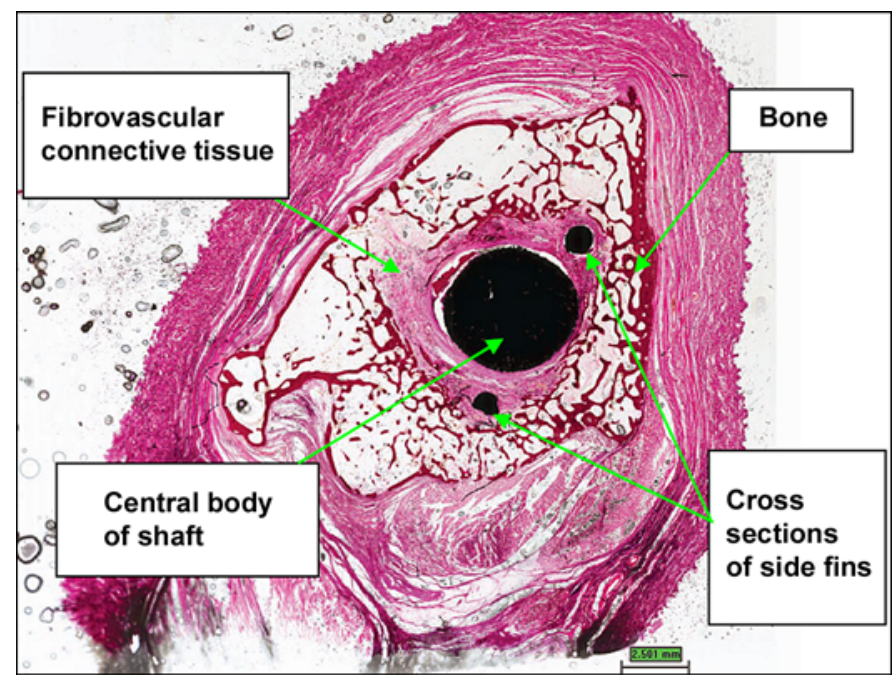

Figure 10.

Cross section of device demonstrating bone-device interface. (hematoxylin and eosin $0.4 \times$ ) in animal 2. Twenty-six weeks after implantation.

around the pylon). There was little to no remodeling of the shaft or endosteal surface. There was no inflammatory response along the pylon.

Implantation of femoral amputation site in animal 3 showed good stability, and a stable, ossified callus that united the femoral shaft to the abutting portion of the pylons was formed. Morphometry measurements indicated a localized interface and apposition area between the callus and the distal pylon at the level of the distal fin. There was optimal biocompatibility of the devices, and no appreciable inflammatory response or encapsulation and no sequestration were found.

\section{DISCUSSION}

The outcomes of the current study are twofold: ingrowth of the surrounding cells into the pores of the 


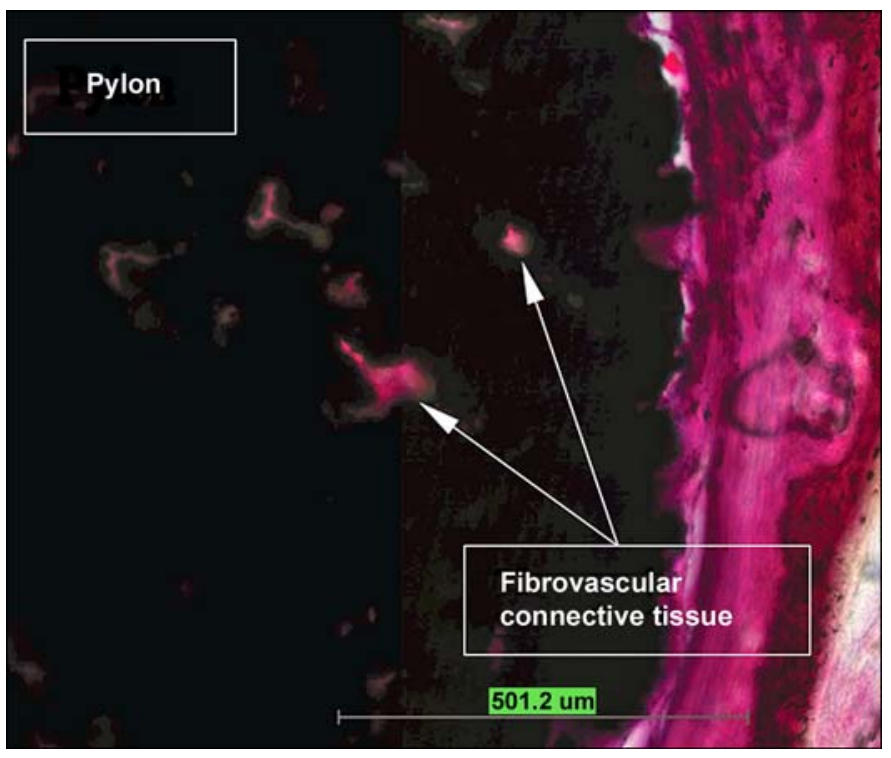

Figure 11.

Pores filled with fibrovascular connective tissue in animal 2 (hematoxylin and eosin 10x).

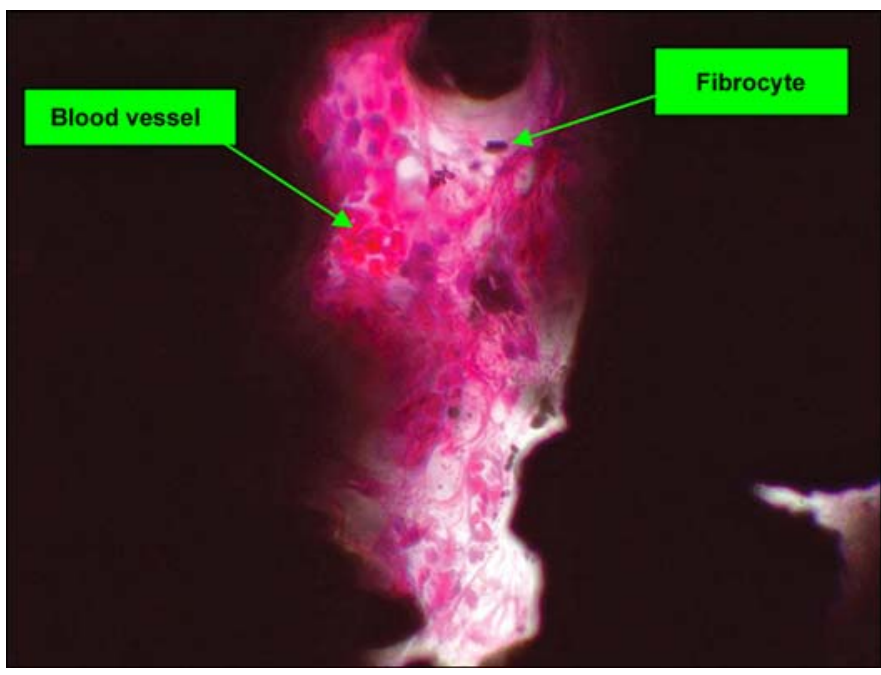

Figure 12.

Pore with fibrovascular tissue (hematoxylin and eosin 40x) in animal 2.

implant, and regeneration of bone in the precut slots in the bone walls.

Relative to the previous report [30], we did not achieve progress in cell adhesion and proliferation. That could be caused by smaller size of the pores $(80-100 \mu \mathrm{m}$ vs $15-250 \mu \mathrm{m})$. Also, due to the extremely thin walls of

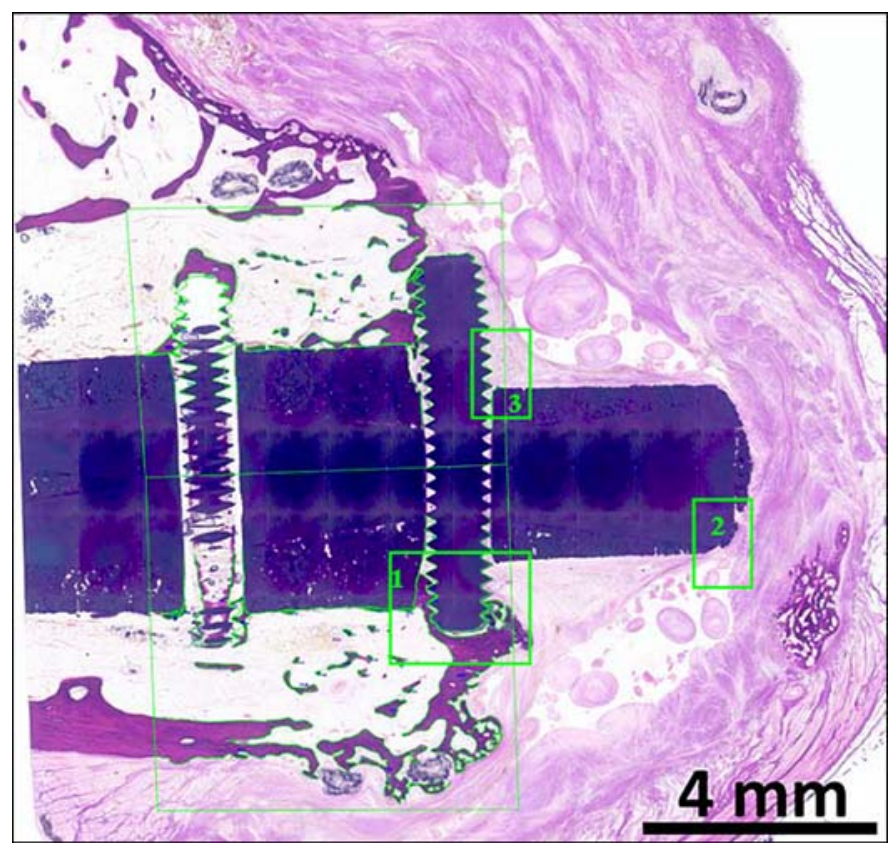

Figure 13.

Morphometry tracings for animal 3 (hematoxylin and eosin). Tibia longitudinal cross section. Composite porous titanium skin and bone integrated pylon with fins (SBIP-3). Green boxes 1, 2, and 3 are detailed in Figures 14, 15, and 16, respectively.

the experimental animals, we could not bore or extensively broach the medullary canal, as it is usually done in DSA, and there was a notable space between the central part of the implant and the bone walls.

With regards to the regeneration of bone in the precut slots, we obtained quite promising results. One of animal 1 's two slots was filled with the new bone, and both slots were filled with the new bone in animals 2 and 3, which had 13 additional weeks for regeneration.

Addition of the side fins to the construct of the implant activated a mechanism of circular remodeling. The longevity of an implant's lifespan in the medullary canal depends on the eventual tightness of the ossification around the inserted shaft. In this paradigm, the vector of remodeling has to be oriented radially, inwardly to the bone's longitudinal axis. The inward direction of remodeling occurs in dental implantation. However, as noted by Pitkin [13], remodeling of the jawbone occurs differently than remodeling inside the medullary canal. The remodeling of the jawbone is directed toward the space occupied by the tooth or the implant. That is a natural feature of the jawbone for keeping the tooth's root in 


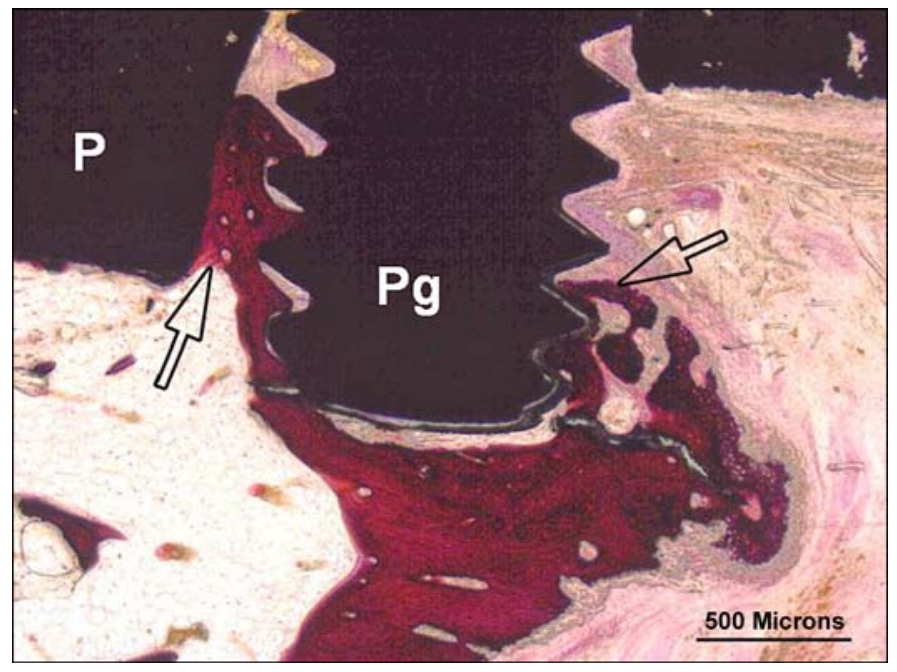

Figure 14.

Animal 3 (hematoxylin and eosin). Composite porous titanium skin and bone integrated pylon with fins (SBIP-3). Tibia longitudinal section. Detail in green box 1 from Figure 13 (distal fin). There is extensive woven bone apposition (arrows) along exposed fin tips $(\mathrm{Pg})$ binding fin to implant $(\mathrm{P})$ and callus.

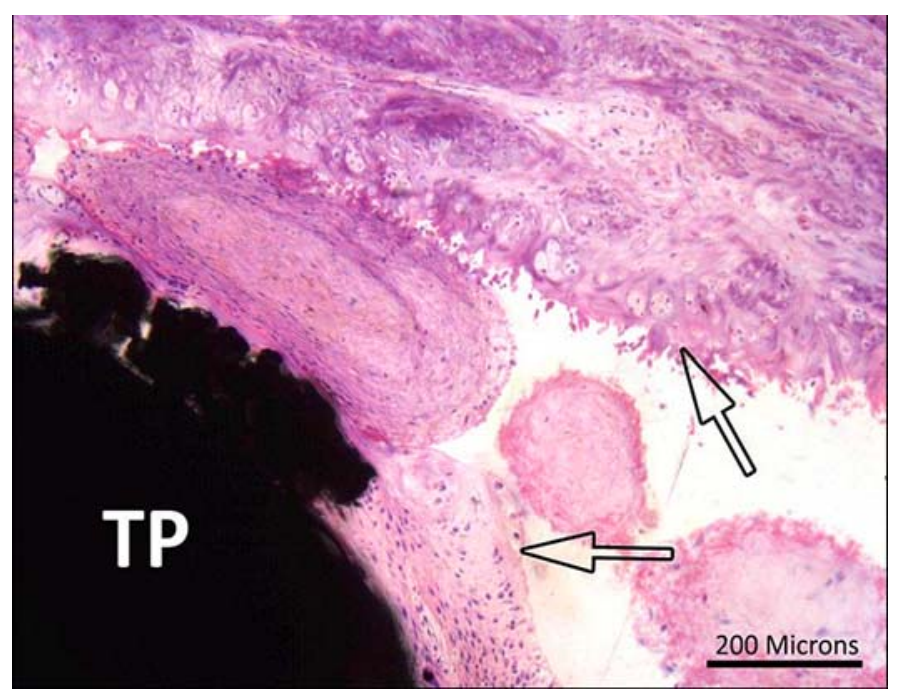

Figure 15.

Animal 3 (hematoxylin and eosin). Composite porous titanium skin and bone integrated pylon with fins (SBIP-3). Tibia longitudinal section. Detail in green box 2 from Figure 13 (distal fin). Arrows = fibrous margins of bursa capping head of pin (TP).

a firm surrounding, which is used in dental implantation. As to the inward remodeling in tubular bones, it is limited by the anatomical dimensions of the medullary canal,

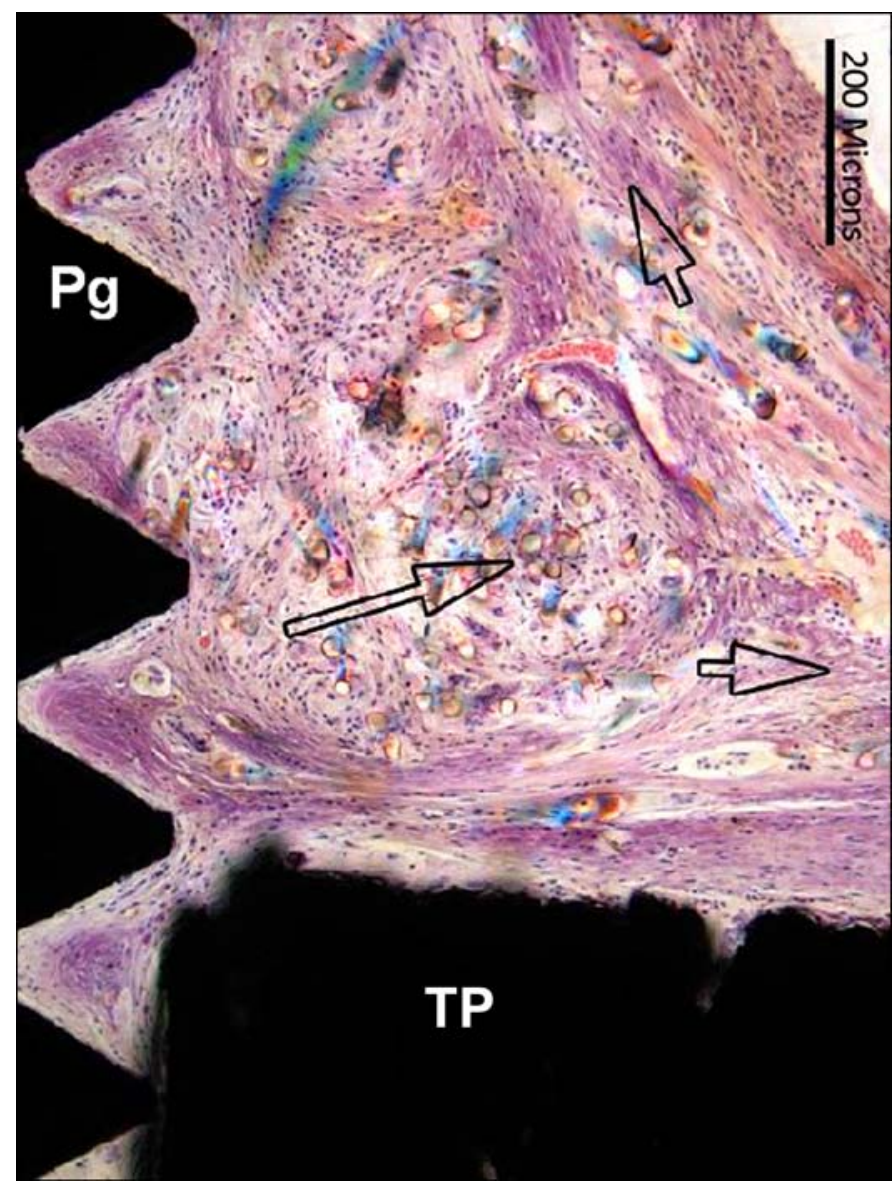

Figure 16.

Animal 3 (hematoxylin and eosin). Tibia longitudinal section. Composite porous titanium skin and bone integrated pylon with fins (SBIP-3). Detail in green box 3 from Figure 13 (distal fin) implant (with 3 pairs of sided pegs). Short arrows = fibrous connective tissue fascicles in direct contact with head of implant (TP) and surface of fin (Pg). Long arrow = birefringent foreign polymer fibers.

where the marrow has to be protected from compressing. A partial inward remodeling is still possible, but only to the extent provided by the boring of the canal before insertion of the stem.

In contrast with the inward remodeling, the bone remodeling in longitudinal and circular directions is a powerful natural mechanism of self-healing, successfully used in distractional osteogenesis [36-37,47]. Thus, the pylon with the side fins (SBIP-3) was designed to utilize the concept of circular remodeling in DSA.

An additional feature of the side fins in SBIP-3 is the antirotational effect, similar to the role of transverse pins 
in Compress Compliant Pre-Stress technology (Biomet Orthopedics, Inc; Warsaw, Indiana) [48-49]. A distinction of the SBIP-3 approach is the activation of the Ilizarov-type (distraction-compression osteogenesis) remodeling of the bone around the fins. This kind of remodeling produces stronger bone tissues [37]. In addition, the SBIP-3 techniques do not require any guiding jigs, which are necessary for inserting the antirotational Compress pins or intramedullary locked nails [49].

Due to the small number of test animals, the pull-out experiments and analysis of the postoperative risk associated with the fin's implantation could not be conducted, but will be included in further studies.

\section{CONCLUSIONS}

- In three rabbits, a pair of slots were precut in the bone walls. An implant for DSA with side fins was fixated inside these slots.

- Histological tests showed a complete remodeling of one slot in animal 1 at 13 weeks after the surgery, and a complete remodeling of both slots in animals 2 and 3 at 26 weeks after surgery.

- Remodeling occurred despite the gap between the central part of the implant and the walls of the medullary canal.

- The study was the first experimental verification of the proposal to use the mechanism of circular bone remodeling for DSA of limb prostheses.

\section{ACKNOWLEDGMENTS}

\section{Author Contributions:}

Study concept and supervision: M. Pitkin.

Design of implants: M. Pitkin.

Drafting of manuscript: M. Pitkin.

Surgical procedures: C. Cassidy, R. Muppavarapu, M. Shevtsov, O. Galibin.

Analysis and interpretation of preclinical data: C. Cassidy, R. Muppavarapu, J. Raymond, M. Shevtsov, O. Galibin, S. D. Rousselle.

Financial Disclosures: The authors have declared that no competing interests exist.

Funding/Support: The material was based on work supported by the Eunice Kennedy Shriver National Institute of Child Health and Human Development, National Institutes of Health (grant R44HD057492). Additional funds came from the Helen and Michael Schaffer Foundation (Boston, Massachusetts).

Disclaimer: The content is solely the responsibility of the authors and does not necessarily represent the official views of the Eunice Ken- nedy Shriver National Institute of Child Health and Human Development or the National Institutes of Health.

\section{REFERENCES}

1. Brånemark R, Brånemark PI, Rydevik B, Myers RR. Osseointegration in skeletal reconstruction and rehabilitation: a review. J Rehabil Res Dev. 2001;38(2):175-81. [PMID:11392650]

2. Hagberg K, Brånemark R. One hundred patients treated with osseointegrated transfemoral amputation prosthesesrehabilitation perspective. J Rehabil Res Dev. 2009;46(3): 331-44. [PMID:19675986] http://dx.doi.org/10.1682/JRRD.2008.06.0080

3. Yang BC, Weng J, Li XD, Yang ZJ, Feng JM, Chen JY, Zhang XD. Preliminary study on HA coating percutaneously implanted in bone. Int J Artif Organs. 1999;22(10): 713-18. [PMID:10585137]

4. Smith TJ, Galm A, Chatterjee S, Wells R, Pedersen S, Parizi AM, Goodship AE, Blunn GW. Modulation of the soft tissue reactions to percutaneous orthopaedic implants. J Orthop Res. 2006;24(7):1377-83. [PMID:16732606] http://dx.doi.org/10.1002/jor.20170

5. Von Recum AF. Applications and failure modes of percutaneous devices: a review. J Biomed Mater Res. 1984;18(4): 323-36. [PMID:6234317] http://dx.doi.org/10.1002/jbm.820180403

6. Furuzono T, Wang PL, Korematsu A, Miyazaki K, OidoMori M, Kowashi Y, Ohura K, Tanaka J, Kishida A. Physical and biological evaluations of sintered hydroxyapatite/ silicone composite with covalent bonding for a percutaneous implant material. J Biomed Mater Res B Appl Biomater. 2003;65(2):217-26. [PMID:12687713] http://dx.doi.org/10.1002/jbm.b.10002

7. Tillander J, Hagberg K, Hagberg L, Brånemark R. Osseointegrated titanium implants for limb prostheses attachments: infectious complications. Clin Orthop Relat Res. 2010; 468(10):2781-88. [PMID:20473597] http://dx.doi.org/10.1007/s11999-010-1370-0

8. Hassaballa M, Mehendale S, Poniatowski S, Kalantzis G, Smith E, Learmonth ID. Subsidence of the stem after impaction bone grafting for revision hip replacement using irradiated bone. J Bone Joint Surg Br. 2009;91(1):37-43. [PMID:19092002] http://dx.doi.org/10.1302/0301-620X.91B1.20376

9. Mandalia V, Eyres K, Schranz P, Toms AD. Evaluation of patients with a painful total knee replacement. J Bone Joint Surg Br. 2008;90(3):265-71. [PMID:18310744] http://dx.doi.org/10.1302/0301-620X.90B3.20140

10. Kawamura H, Dunbar MJ, Murray P, Bourne RB, Rorabeck $\mathrm{CH}$. The porous coated anatomic total hip replacement. A 
ten to fourteen-year follow-up study of a cementless total hip arthroplasty. J Bone Joint Surg Am. 2001;83-A(9): 1333-38. [PMID:11568195]

11. Berend ME, Ritter MA, Meding JB, Davis P. Twenty-one years clinical experience of 461 femoral revision total hip arthroplasties with a calcar replacement prosthesis. The Duke Orthop J. 2012;2(1):1-4. http://dx.doi.org/10.5005/jp-journals-10017-1010

12. Frossard LA, Tranberg R, Haggstrom E, Pearcy M, Brånemark R. Load on osseointegrated fixation of a transfemoral amputee during a fall: loading, descent, impact and recovery analysis. Prosthet Orthot Int. 2010;34(1):85-97. [PMID:20196690] http://dx.doi.org/10.3109/03093640903585024

13. Pitkin M. One lesson from arthroplasty to osseointegration in search for better fixation of in-bone implanted prosthesis. J Rehabil Res Dev. 2008;45(4):vii-xiv. [PMID:18712634]

14. Helgason B, Pálsson H, Rúnarsson TP, Frossard L, Viceconti M. Risk of failure during gait for direct skeletal attachment of a femoral prosthesis: a finite element study. Med Eng Phys. 2009;31(5):595-600. [PMID:19150253] http://dx.doi.org/10.1016/j.medengphy.2008.11.015

15. Huiskes R, Weinans H, van Rietbergen B. The relationship between stress shielding and bone resorption around total hip stems and the effects of flexible materials. Clin Orthop Relat Res. 1992;(274):124-34. [PMID:1728998]

16. Rosenbaum Chou TG, Child JR, Naughtin RJ, Rigdon RR, Schumann C, Bloebaum RD. The relationship between femoral periprosthetic cortical bone geometry and porosity after total hip arthroplasty. J Biomed Mater Res A. 2008; 87(1):107-15. [PMID:18085646] http://dx.doi.org/10.1002/jbm.a.31702

17. Tomaszewski PK, van Diest M, Bulstra SK, Verdonschot N, Verkerke GJ. Numerical analysis of an osseointegrated prosthesis fixation with reduced bone failure risk and periprosthetic bone loss. J Biomech. 2012;45(11):1875-80. [PMID:22677337] http://dx.doi.org/10.1016/j.jbiomech.2012.05.032

18. Nebergall A, Bragdon C, Antonellis A, Kärrholm J, Brånemark R, Malchau H. Stable fixation of an osseointegated implant system for above-the-knee amputees: titel RSA and radiographic evaluation of migration and bone remodeling in 55 cases. Acta Orthop. 2012;83(2):121-28.

[PMID:22489885]

http://dx.doi.org/10.3109/17453674.2012.678799

19. Frossard L, Stevenson N, Sullivan J, Uden M, Pearcy M. Categorization of activities of daily living of lower limb amputees during short-term use of a portable kinetic recording system: A preliminary study. J Prosthet Orthot. 2011;23(1):2-11. http://dx.doi.org/10.1097/JPO.0b013e318207914c
20. Lee WC, Frossard LA, Hagberg K, Haggstrom E, Gow DL, Gray S, Brånemark R. Magnitude and variability of loading on the osseointegrated implant of transfemoral amputees during walking. Med Eng Phys. 2008;30(7):825-33.

[PMID:17977050]

http://dx.doi.org/10.1016/j.medengphy.2007.09.003

21. Pitkin M, Raykhtsaum G, inventors. Skin integrated device. United States patent US 8,257,435. 2012 Sep 4.

22. Pitkin M, Blinova MI, Yudintseva NV, Potokin IL, Raykhtsaum G, Pinaev GP. Skin and bone integrated prosthetic technology. I. Characterization and morphology of human cells cultivated on titanium implants of different structures [abstract]. In: Proceedings of the 9th Russian National Congress, People and Health: 2004 Nov 22-26; St. Petersburg, Russia. St. Petersburg: Russian National Congress; 2004. p. 217.

23. Shelton TJ, Beck JP, Bloebaum RD, Bachus KN. Percutaneous osseointegrated prostheses for amputees: Limb compensation in a 12-month ovine model. J Biomech. 2011;44(15):2601-6. [PMID:21920525]

http://dx.doi.org/10.1016/j.jbiomech.2011.08.020

24. Aschoff HH, Kennon RE, Keggi JM, Rubin LE. Transcutaneous, distal femoral, intramedullary attachment for abovethe-knee prostheses: an endo-exo device. J Bone Joint Surg Am. 2010;92(Suppl 2):180-86. [PMID:21123601] http://dx.doi.org/10.2106/JBJS.J.00806

25. Kang NV, Pendegrass C, Marks L, Blunn G. Osseocutaneous integration of an intraosseous transcutaneous amputation prosthesis implant used for reconstruction of a transhumeral amputee: case report. J Hand Surg Am. 2010;35(7):1130-34. [PMID:20541327]

http://dx.doi.org/10.1016/j.jhsa.2010.03.037

26. Pitkin M. Design features of implants for direct skeletal attachment of limb prostheses. J Biomed Mater Res A. 2013 Apr 2. [PMID:23554122] http://dx.doi.org/10.1002/jbm.a.34606

27. Pitkin M, Raykhtsaum G, Galibin OV, Protasov MV, Chihovskaya JV, Belyaeva IG. Skin and bone integrated prosthetic pylon: a pilot animal study. J Rehabil Res Dev. 2006;43(4):573-80. [PMID:17123195] http://dx.doi.org/10.1682/JRRD.2005.05.0160

28. Pitkin M, Raykhtsaum G, Pilling J, Galibin OV, Protasov MV, Chihovskaya JV, Belyaeva IG, Blinova MI, Yudintseva NM, Potokin IL, Pinaev GP, Moxson V, Duz V. Porous composite prosthetic pylon for integration with skin and bone. J Rehabil Res Dev. 2007;44(5):723-38.

[PMID:17943684]

http://dx.doi.org/10.1682/JRRD.2006.12.0160

29. Farrell BJ, Prilutsky BI, Ritter JM, Kelley S, Popat K, Pitkin M. Effects of pore size, implantation time, and nanosurface properties on rat skin ingrowth into percutaneous porous titanium implants. J Biomed Mater Res A. 2013 
May 23. [PMID:23703928]

http://dx.doi.org/10.1002/jbm.a.34807

30. Pitkin M, Raykhtsaum G, Pilling J, Shukeylo Y, Moxson V, Duz V, Lewandowski J, Connolly R, Kistenberg RS, Dalton JF 4th, Prilutsky B, Jacobson S. Mathematical modeling and mechanical and histopathological testing of porous prosthetic pylon for direct skeletal attachment. J Rehabil Res Dev. 2009;46(3):315-30. [PMID:19675985] http://dx.doi.org/10.1682/JRRD.2008.09.0123

31. Pitkin M, Pilling J, Raykhtsaum G. Mechanical properties of totally permeable titanium composite pylon for direct skeletal attachment. J Biomed Mater Res B Appl Biomater. 2012;100(4):993-99. [PMID:22287509] http://dx.doi.org/10.1002/jbm.b.32663

32. Liu X, Wu S, Yeung KW, Chan YL, Hu T, Xu Z, Liu X, Chung JC, Cheung KM, Chu PK. Relationship between osseointegration and superelastic biomechanics in porous NiTi scaffolds. Biomaterials. 2011;32(2):330-38.

[PMID:20869110] http://dx.doi.org/10.1016/j.biomaterials.2010.08.102

33. Navarro M, Michiardi A, Castaño O, Planell JA. Biomaterials in orthopaedics. J R Soc Interface. 2008;5(27):1137-58. [PMID: 18667387] http://dx.doi.org/10.1098/rsif.2008.0151

34. Pitkin $M$, inventor. In-bone implantable shaft for prosthetic joints or for direct skeletal attachment of external limb prostheses and method of its installation. US patent application 11/899068. 2007.

35. Pitkin M. On the way to total integration of prosthetic pylon with residuum. J Rehabil Res Dev. 2009;46(3):345-60. [PMID:19675987] http://dx.doi.org/10.1682/JRRD.2008.08.0112

36. Ilizarov GA. The principles of the Ilizarov method. Bull Hosp Jt Dis Orthop Inst. 1988;48(1):1-11. [PMID:2840141]

37. Ilizarov GA. The tension-stress effect on the genesis and growth of tissues. Part I. The influence of stability of fixation and soft-tissue preservation. Clin Orthop Relat Res. 1989;(238):249-81. [PMID:2910611]

38. Pitkin M, Shevtsov M, Yudentsova N, Blinova M, Pinaev G, Potokin I, Protasov M, Suslov D, Ivanova A, Savchenko O, Galibin O. Application of the basic principle of distraction osteogenesis to in-bone implantation. In: Proceedings of 4th International Conference on Advances in Orthopaedic Osseointegration; 2012 Feb 10-12; San Francisco, CA. Orthopaedic Surgical Osseointegration Society; 2012. p. 23.

39. Pitkin M, Cassidy C, Muppavarapu R, Edell D. Recording of electric signal passing through a pylon in direct skeletal attachment of leg prostheses with neuromuscular control. IEEE Trans Biomed Eng. 2012;59(5):1349-53.

[PMID:22345523]

http://dx.doi.org/10.1109/TBME.2012.2187784
40. Clemow AJ, Weinstein AM, Klawitter JJ, Koeneman J, Anderson J. Interface mechanics of porous titanium implants. J Biomed Mater Res. 1981;15(1):73-82.

[PMID:7348706]

http://dx.doi.org/10.1002/jbm.820150111

41. Blinova MI, Yudintzeva NM, Nikolaenko NS, Potokin IL, Raykhtsaum G, Pitkin MR, Pinaev GP. Cell cultivation on porous titanium implants with various structures. Cell Tissue Biol. 2010;4(6):572-79. [PMID:21949585] http://dx.doi.org/10.1134/S1990519X10060088

42. El Sayegh TY, Pilliar RM, McCulloch CA. Attachment, spreading, and matrix formation by human gingival fibroblasts on porous-structured titanium alloy and calcium polyphosphate substrates. J Biomed Mater Res. 2002;61(3): 482-92. [PMID:12115474] http://dx.doi.org/10.1002/jbm.10217

43. Itälä AI, Ylänen HO, Ekholm C, Karlsson KH, Aro HT. Pore diameter of more than 100 microm is not requisite for bone ingrowth in rabbits. $\mathrm{J}$ Biomed Mater Res. 2001;58(6):679-83. [PMID:11745521] http://dx.doi.org/10.1002/jbm.1069

44. Cheung S, Gauthier M, Lefebvre LP, Dunbar M, Filiaggi M. Fibroblastic interactions with high-porosity Ti-6Al-4V metal foam. J Biomed Mater Res B Appl Biomater. 2007; 82(2):440-49. [PMID:17245747] http://dx.doi.org/10.1002/jbm.b.30749

45. Raymond J. Summary of histopathologic evaluation of titanium pylon devices implanted in two rabbits for Poly-Orth International. Frederick (MD): Charles River Pathology Associates; 2010. Report No.:20006108.

46. Rousselle SD. Skin-bone implant interface. Executive summary for Poly-Orth International. Thurmont (MD): Alizée Pathology, LLC; 2012. Project FEE12-312.

47. Ilizarov GA. The tension-stress effect on the genesis and growth of tissues: Part II. The influence of the rate and frequency of distraction. Clin Orthop Relat Res. 1989;(239): 263-85. [PMID:2912628]

48. Pedtke AC, Wustrack RL, Fang AS, Grimer RJ, O’Donnell RJ. Aseptic failure: how does the Compress(®) implant compare to cemented stems? Clin Orthop Relat Res. 2012; 470(3):735-42. [PMID:22045069]

http://dx.doi.org/10.1007/s11999-011-2159-5

49. Kempf I, Leung KS, Grosse A. Practice of intramedullary locked nails. New York: Springer; 2002.

Submitted for publication November 4, 2012. Accepted January 22, 2013.

This article and any supplemental material should be cited as follows:

Pitkin M, Cassidy C, Muppavarapu R, Raymond J, Shevtsov M, Galibin O, Rousselle SD. New method of 
JRRD, Volume 50, Number 5, 2013

fixation of in-bone implanted prosthesis. J Rehabil Res

Dev. 2013;50(5):709-22.

http://dx.doi.org/10.1682/JRRD.2012.11.0202

\begin{tabular}{|c|c|}
\hline $\begin{array}{l}\text { nu suenssions scregene or: } \\
\text { iThenticate" }\end{array}$ & Crosstef НЕнев \\
\hline Went Tor & 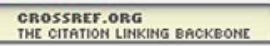 \\
\hline
\end{tabular}

